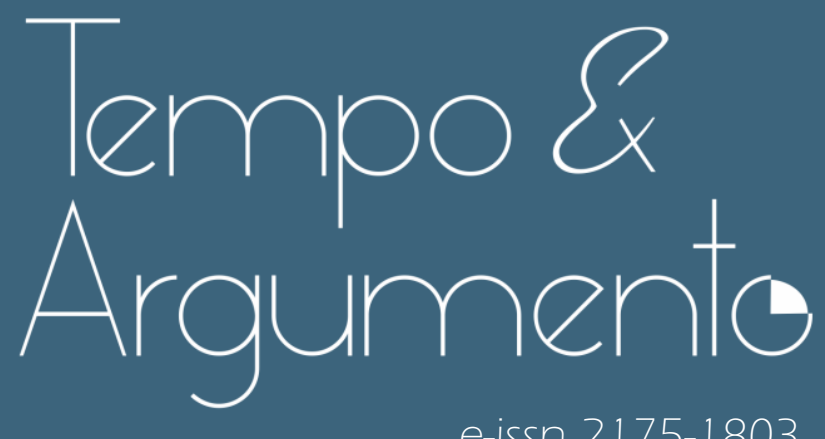

e-issn 2175-1803

\title{
Reconhecendo gêneros, desconstruindo poderes: a literatura como transgressão verbal
}

- Vanessa Ribeiro Simon Cavalcanti

Doutora em História pela Universidade de Leon (UNILEON - Espanha).

Professora do Programa de Pós-Graduação em Família na Sociedade

Contemporânea e do Programa de Pós-Graduação em Políticas Sociais e Cidadania da Universidade Católica do Salvador (PPGFSC/UCSAL). Professora do Programa de Pós-Graduação em Estudos Interdisciplinares sobre Mulheres, Gênero e Feminismo da Universidade Federal da Bahia (PPGNEIM/UFBA).

Salvador, BA - BRASIL lattes.cnpq.br/6538283866214716

vanessa.cavalcanti@uol.com.br

(iD)

orcid.org/0000-0002-5689-8206

- Antonio Carlos da Silva

Doutor em Ciências Sociais pela Universidade de Leon (UNILEON - Espanha) e Universidade Federal da Bahia (UFBA). Estágio Pós-Doutoral na Universidade de Coimbra (Portugal). Professor do Programa de Pós-Graduação em Políticas Sociais e Cidadania da da Universidade Católica do Salvador (PPGPSC/UCSAL). Coordenador do Núcleo de Estudos sobre Educação e Direitos Humanos (NEDH/UCSAL/CNPq).

Salvador, BA - BRASIL lattes.cnpq.br/2735855153608701

carlos.zamora@uol.com.br

(D) orcid.org/0000-0003-3316-5795

Para citar este artigo:

CAVALCANTI, Vanessa Ribeiro Simon; SILVA, Antonio Carlos da. Reconhecendo gêneros, desconstruindo poderes: a literatura como transgressão verbal. Tempo e Argumento, Florianópolis, v. 12, n. 31, e0202, set./dez. 2020.

doi)

http://dx.doi.org/10.5965/2175180312312020e0202

Recebido: 05/08/2019

Aprovado: 30/06/2020 


\title{
Reconhecendo gêneros, desconstruindo poderes: a literatura como transgressão verbal
}

\begin{abstract}
Resumo
Tendo a escritura literária como recurso e fonte, o presente artigo delineia questões sobre gênero e poder, observando o estilo ensaístico e uma abordagem a partir da Teoria Crítica, com foco na produção feminista alemã e norteamericana contemporânea. Dentro de um contexto paradoxal, pensar e produzir expressões que enfatizam a necessária construção de solidariedades e lutas comuns contra o patriarcado, o colonialismo e o capitalismo, tanto o acervo clássico quanto contemporâneo trazem matéria-prima e fontes históricas escritas - para compreender as ontologias do poder e o reconhecimento da categoria gênero. Desse modo, a metodologia delineada é de caráter qualitativo, com base documental em obras literárias que retrataram formas de transgressão (aos papéis e funções vinculadas às mulheres e à vida privada e domésticofamiliar) e mirada crítico-cultural. A aproximação com epistemologias feministas e produção historiográfica contemporânea permitiram descritivo histórico, mas especialmente fundamentos teóricos de interpretação para uma abordagem ética, inclusiva, justa.
\end{abstract}

Palavras-chave: História. Identidade de Gênero. Literatura. Teoria do Conhecimento. Poder (Filosofia).

\section{Recognizing genres, deconstructing powers: a literature like verbal transgression}

\begin{abstract}
With literary writing as a resource and source, this article outlines questions about gender and power, observing the essay style and an approach based on Critical Theory, focusing on contemporary German and American feminist production. Within a paradoxical context, thinking and producing expressions that emphasize the necessary construction of solidarity and common struggles against patriarchy, colonialism and capitalism, both the classic and contemporary collections bring raw material and historical - written - sources to understand ontologies of power and the recognition of the gender category. In this way, the methodology outlined is of a qualitative character, based on documents in literary works that portrayed forms of transgression (to the roles and functions linked to women and to private and domestic-family life) and critical-cultural view. The approach with feminist epistemologies and contemporary historiographical production allowed historical description, but especially theoretical foundations of interpretation for an ethical, inclusive, fair approach.
\end{abstract}

Keywords: History. Gender identity. Literature. Theory of Knowledge. Power (Philosophy). 


\section{Abrindo as cortinas: cenários e epistemologias}

Não há calamidade pior do que a anarquia, que leva aos povos seus imensos males. Ela destrói a polis, arrasa suas casas, e, na batalha, rompe as fileiras de lanças,

antecipando a derrota. Mas aquele que segue o caminho da obediência, pode ser salvo por ela. Por isso defendemos os que respeitam a ordem e não podemos deixar que uma mulher nos derrote. Melhor seria perder o poder pela mão de um homem, do que fraquejar diante de uma mulher inferior. (SÓFOCLES, 2014, p. 51)

Entre permanências e rupturas no que concerne às expectativas e sentidos dados às mulheres, a literatura sempre trouxe um campo de possibilidade e de vertentes que ultrapassaram - seja pela própria escrita ou escritura de mulheres sobre mulheres - um viés que permite também saltar delineamentos cronológicos e observados como constantes "evoluções". A sociedade baseada em todos os aspectos de mercantilização e objetificação da vida - referência ao atual campo histórico da Modernidade, tomando como base uma contínua transformação de trabalho abstrato em mais dinheiro - busca ocultar uma orientação patriarcal e racista na qual a questão de gênero não é reconhecida como um processo de dissociação de valor (SCHOLZ, 2017). São trilhas que advêm da Teoria Crítica, especialmente da Teoria do Valor alemã e crítica literária comparada norte-americana.

Ao longo de todo o século XX e primeiras décadas do XXI, mesmo com ondas feministas e acirradas polarizações sobre papel, função, ideologias, ademais da força da tradição (religiosa e moral), movimentos sociais e políticos são intensificados. Todas as atividades naturalizadas em sua correspondência negativa com a acumulação de capital, dialeticamente, são atribuídas às mulheres, ganhando esforços e reforços quando regimes democráticos se desestabilizam ou ganham nuances conservadoras. Precedentes históricos remontam ao período helênico, mas tal entendimento ontológico, portanto impeditivo de reflexão frente à universalidade abstrata na forma mercadoria (KURZ, 2015), é uma pré-condição da chamada Modernidade. 
De análises acadêmicas às múltiplas referências em outras linguagens e expressões de Humanidade, a literatura é abundante em referências. Do período revolucionário europeu, com Mary Wollstonecraft a Olympe de Gouges, as existencialistas Virgínia Woolf e Simone de Beauvoir. Nesta lista, apesar de subjetiva, constam a angolana Paula Tavares, a nigeriana Chimamanda Ngozi Adichie e a poetisa moçambicana Noémia de Sousa. Sem olvidar dos contributos latino-americanos contemporâneos em Teresa Cárdenas (Cuba), Selva Almada (Argentina), Lina Meruane (Chile), Carolina de Jesus e Heloísa Buarque de Hollanda (Brasil). A escritura e a escrita - independentemente de inseridas em contextos acadêmicos - tomaram dimensões e assimilaram bandeiras, lutas e movimentos. A originalidade, porquanto, não está matizada pelas obras de referências, mas pela possibilidade de conexão entre tempos, temporalidades e críticas redigidas, narradas e espelhadas em seus determinados momentos históricos.

O universo é ilimitado, para todos os gostos e especificações teóricas. De abordagens mais privadas e cotidianas àquelas que tomam as palavras com toda potência. O importante é não perder de vista, frente às idiossincrasias do capital, - elemento díspare entre a propriedade/filiação (como elemento masculino/patriarcal/colonial) e a representação do feminino nessas abordagens. Em especial, aqui o nosso interesse investigativo - apresentado sob forma de ensaio -, sobre o papel do Estado como instituição não dissociada do Poder e determinado ideologicamente para manutenção das estruturas vigentes.

Destarte, elegemos a leitura de "Antígona" (SÓFOCLES, 2014), em correspondência dialética com as lentes críticas da filósofa Judith Butler, e Cassandra - na poética de Christa Wolf - para abarcar um fenômeno recorrente na Modernidade: a barbárie - que insiste em perdurar mesmo em situações de contínua crise" e desvela uma situação paradoxal de "asselvajamento do patriarcado" (SCHOLZ, 2007). A mitologia serve como base e fonte originária da

\footnotetext{
Crise para além de um superficial momento de racionalização para enfrentar a irracionalidade econômica (HARVEY, 2011). Isso porque, "a lógica identitária do princípio de valorização não causa o eterno retorno do mesmo, mas um processo histórico irreversível com situações qualitativamente diversas [...] De cada vez que se esgota uma determinada fase de valorização, também as instituições, os conceitos e as ideologias políticas que a ela se encontram associados se tornam obsoletos (KURZ, 2015, p. 39, grifos dos autores).
} 
intepretação e leituras possíveis realizadas por duas autoras contemporâneas, integradas à historiografia crítica alemã e norte-americana. Ambas, de origem judaica, trazem questões centrais para analisar os tempos nos quais estão inseridas e com forte produção de e com mulheres, reforçando datação a partir dos anos 80.

A narrativa da tragédia grega, corroborando a filósofa norte-americana, expõe (para além dos atributos da vontade e do pensamento) uma manifesta relação de poder e hierarquia na forma social. Qual o propósito de quem fala? Há uma identificação manifesta com os interesses e liberdades individuais ou a ênfase encobre a legitimação da violência por intermédio do ethos coletivo? 0 direito a ter direitos, que se torna o cerne da ação política empregada por Antígona ao confrontar as Leis que definem quem tem o direito ao luto - aqui um preâmbulo totalitário que repercutirá nas guerras de ordenamento mundial do final do século XX e início do século XXI - não difere da exclusão das mulheres do espaço público destinado ao fazer política².

Nessa contribuição à crítica da sociedade contemporânea, buscamos engendrar um constante diálogo com a Teoria do Valor (fetichismo, alienação e dissociação do valor) para compreender as contradições e os seus limites internos. As mulheres, de responsáveis pela organização do lar (fetichismo doméstico), após as conquistas no plano político e econômico - sufrágio e a inserção no mercado de trabalho - passam a ser reconhecidas, também, com sujeitos modernos do Direito. Ou seja, as suas relações, anteriormente dissociadas da lógica da acumulação, tornam-se relações contratuais na forma mercadoria. Sob orientação dialética, são realocadas da "esfera reprodutiva para a esfera profissional (mantendo simultaneamente a responsabilidade principal pela esfera da reprodução)" (SCHOLZ, 2017, p. 2).

Não confundir, entretanto, a lógica da dissociação do valor na categorização de identidade com um princípio da troca. Trata-se, mais do que uma medida de tempo social médio para estabelecer substância ao valor e, por

\footnotetext{
${ }^{2}$ Uma explícita divisão do espaço público (política) e do espaço privado (economia), na qual a primeira é uma ação especificamente masculina - possível em decorrência da sua alienação dos afazeres domésticos e da salvaguarda da vida. As atividades econômicas, espaço privado, são exercidas por mulheres e dissociadas da lógica da acumulação de capital.
} 
conseguinte, promover o seu equivalente monetário (forma dinheiro), de um problema de gênero. Há uma separação, nada contingente, em conotar as expressões do feminino ao trabalho dissociado e obscuro na formação do valor. Essa diferenciação é a base da sociedade patriarcal, não um tema secundário do moderno sistema produtor de mercadorias. O que corresponde ao traço benjaminiano presente em Cassandra, que ao questionar o fazer história com base na barbárie, desvela o tripé da Modernidade: a dominação, a propriedade privada e o patriarcado.

Em momentos de crise do sistema e de retomada de vertentes conservadoras, cada vez mais frequentes e em espaços mais curtos, a busca por novas formas de aumentar a produtividade e manter-se competitivo exigem estratégias que ampliam as diferenças e aumentam o grau de violência de gênero. As decorrentes taxas de desemprego resultantes dessa lógica irracional para aumentar o processo de acumulação, consequentemente descortinam o medo pela histórica desvalorização e, mesmo sob a égide do crédito como substituto na produção de mais valor, revelam um recrudescer da barbárie nas relações sociais sob a forma mercadoria. Os tempos sombrios (ARENDT, 2006) ou de austeridade difusa são os matizes limitrofes de ações, reações e expressões de polaridades e exigências de tentar analisar criticamente o processo.

Isto não tem nada a ver com a hipostasiação da diferença que se pode encontrar nas teorias pós-estruturalistas; pelo contrário, para a crítica da lógica da identidade no sentido da crítica da dissociação-valor trata-se de uma determinação de conceito e diferenciação centrada na coisa. Em vez disso, a hipostasiação da diferença da pós-modernidade corresponde ao asselvajamento do patriarcado capitalista no plano da elaboração teórica. (SCHOLZ, 2017, p. 3)

Neste panorama, questionar a representação do Estado, como unidade política exclusiva para abarcar questões de interesse coletivo, torna-se uma negação do próprio processo de agir politicamente. O Estado e suas instâncias, no atual campo histórico da Modernidade, são objetos à crítica do próprio conceito de política - que é patriarcal em sua essência, bárbaro e aniquilador de alteridades; machista e despótico na divisão dos espaços público e privado. 
Não como um dado ontológico, previamente existente, mas como um conceito historicamente limitado que pertence à história da implementação do moderno sistema produtor de mercadorias [...] que estabeleceram condições de trabalho modernas, mas não alteram a essência do sistema de produção de mercadorias. (KURZ, 1997, p. 81)

Aqui, uma diferença básica, o sistema político, sob o manto democrático em uma sociedade que vigora a constante transformação de trabalho abstrato em mais dinheiro, tem por missão assegurar a estabilidade do poder, organizar a forma social e regular a atividade econômica. Por conseguinte, são ações policialescas, responsáveis pela promoção de violência contra aqueles grupos (ditos minoritários) que, para além da condição precária, estão constantemente expostos à precariedade ${ }^{3}$. Às mulheres, uma condição de não reconhecimento de sua condição como sujeitos históricos, para além da dissociação do valor, a alienação de sua liberdade individual para definir ações políticas emancipatórias e não condizentes com o fetiche da mercadoria. Sempre vinculadas aos contextos privados e domésticos, estando restritas às competências do cuidado e da manutenção da vida familiar.

É precisamente a ascensão do princípio masculino do trabalho abstrato como um tautológico fim em si mesmo que traz como resultado o confinamento doméstico e a repressão da mulher na história ocidental, produzindo, ao fim e ao cabo, a perda da dimensão sensível das relações humanas, a destruição da natureza e a ameaça de guerra nuclear. (SCHOLZ, 1996, p. 16)

\section{Antígona: Quais vidas são legítimas de serem vivíveis?}

Considerando que o exercício da liberdade é uma herança grega, pois se define como a raison d'être da política (ARENDT, 2006), a abordagem dialética de Butler sobre a relação Liberdade/Poder desvela uma curiosa leitura do papel do Estado na conformação do lugar (portanto, território) da mulher nas sociedades contemporâneas. Antígona está a questionar o ethos coletivo ao confrontar a

\footnotetext{
${ }^{3}$ Duas categorias-chave para Judith Butler contribuir à crítica da sociedade moderna. A "condição precária”, que abarca a todos/as que estão sob os efeitos da sociedade da mercadoria, e "precariedade", as chamadas minorias que estão constantemente expostas à violência e sem qualquer apoio das instituições do Estado na criação/aplicação de políticas protetivas (BUTLER, 2011; 2018).
} 
decisão do Rei Creonte sobre o direito de realizar as honras fúnebres do seu irmão Polinices ${ }^{4}$.

A legitimidade da violência aqui empregada, negar as honrarias e o direito ao luto, é vista por Antígona como uma decisão unilateral, decerto não democrática, pois não condiz com a harmonia entre os interesses coletivos e a liberdade do indivíduo. Sendo mulher, um agravante nas relações de poder, pois tampouco é reconhecida como cidadã plena de direitos a ter direitos. Acima de tudo, de questionar a legitimidade desse poder, quando este é empregado para garantir a estabilidade por intermédio da violência e/ou ausência de políticas protetivas para minorias.

Que honra mais sublima poderia haver para mim do que prestar honras fúnebres ao meu irmão? Todos esses diriam que aprovam o que eu fiz, se o terror não travasse suas línguas. Mas é privilégio do poder tirano fazer e dizer tudo o que deseja. (SOFÓCLES, 2014, p. 43)

Antígona, o corpo que manifesta (voz e performance) o paradoxo do poder democrático, estabelece um marco na literatura política e filosófica. Quiçá uma prévia para Melville (2017) criar o seu Bartleby, pois o "prefiro não fazer" do escriturário retoma o imperativo "confirmo o que fiz. Não o nego, absolutamente" de Antígona ao enfrentar Creonte. O que ela está a negar é o poder conferido ao tio/Rei sem qualquer reconhecimento ou mérito que não a transmissão por via titular (herança e propriedade).

Quando ela aparece diante de Creonte, ela age novamente, agora verbalmente, recusando-se a negar seu envolvimento direto no ato. Com efeito, o que ela rejeita é a possibilidade linguística de se separar do fato, afirmando-o de maneira ambígua, sem se entregar, sem dizer simplesmente "eu fiz". (BUTLER, 2001, p. 22)

\footnotetext{
${ }^{4}$ Antígona encerra a trilogia elaborada por Sófocles (Século IV a.C.) sobre a tragédia do Rei Édipo que, após consultar o oráculo de Delfos e ser elucidado sobre a sua maldição, perfura os próprios olhos por não reconhecer em Jocasta, a mãe de seus quatro filhos (Etéocles, Polinices, Antígona e Ismênia), a sua própria Mãe. Com o autoexílio em Atenas, seguido apenas de sua filha Antígona, o trono de Tebas é reconhecido ao irmão de Jocasta, Creonte, até que os filhos varões de Édipo, Etéocles e Policines, possam atingir a maioridade e reclamar o Poder. Em acordo, os dois irmãos decidem governar alternadamente, mas Etéocles se recusa a repassar as honras para o irmão. Policines decide confrontá-lo em batalha para resgatar a coroa de Tebas. O final, elemento-chave da tragédia, resulta na morte dos dois, sendo que as honras fúnebres são legitimadas apenas para Etéocles. Policines é considerado traidor e infiel, sendo, por Cleonte, alienado de qualquer honraria.
} 
Antígona, aqui a negação hegeliana entre o transcendente e o imanente, assume uma postura de embate pelo espaço público, questiona (implicitamente) a unidade do Estado como único elemento para realizar a ação política. Põe em dúvida a categoria representação, pois não reconhece no tio/Rei nada mais do que uma afronta ao "fazer política" e promover a liberdade individual.

Se entendermos o político no sentido da polis, o seu fim ou raison d'être seria estabelecer ou preservar um espaço onde a liberdade como virtuosismo pode aparecer. Está é a esfera onde a liberdade é entendida como realidade terrena, concretizada em palavras que podem ser ouvidas, em feitos que podem ser vistos, e em acontecimentos que podem ser discutidos, recordados e convertidos em narrações, antes de serem por fim incorporados no conjunto das grandes narrativas da história humana. (ARENDT, 2006, p. 166)

A alusiva reflexão de Antígona sobre a relação entre a sociedade e o Estado confere ao debate uma atualidade inequívoca. Ademais da referência grega, na qual são "eles" que determinam o tipo de Estado responsável pela organização política, Antígona representa a alegoria dos povos colonizados (física e espiritualmente), em que o Estado é um elemento externo e os cidadãos/ãs é que são subordinados ao exercício do poder.

Talvez uma primeira ação de desobediência civil, antecipando o julgamento público de Sócrates e orientando a postura crítica de Thoreau sobre a "máquina estatal de guerra", Antígona não consegue se apropriar do ethos coletivo e questiona o espírito das Leis.

Sim, pois para mim, não foi Zeus que a decretou, e nem Dike [...] que deu aos homens semelhantes leis. Os teus decretos não têm o poder de obrigar um mortal a desobedecer às leis dos deuses, pois embora não escritas, elas são poderosas e imutáveis. (SOFÓCLES, 2014, p. 41-42)

Deuses e deusas que dialeticamente correspondem à criação humana, o antecipar do corpo científico que buscava interpretar os fenômenos (ainda) incompreensíveis da natureza. Antígona questiona, implicitamente, o propósito das relações humanas: o viver bem e em comunidade. Outrossim, alude a uma organização social que reconhece as alteridades e que prioriza o vínculo ético 
com o Outro/a Outra, não a moral do Estado que se sustenta por títulos (filiação/herança) e precisa paradoxalmente do axioma transcendente para se autoafirmar como representação do poder.

O que podemos confirmar com a seguinte citação de Creonte:

Ela foi arrogante ao passar por cima de leis publicadas. Também foi arrogante ao zombar e ao se vangloriar pelo que fez. Na verdade, será ela o homem, e não eu, se seus atos não forem punidos energicamente. Ainda que seja filha de minha irmã de sangue, e estejamos unidos pelo poder supremo de Zeus. (SOFÓCLES, 2014, p. 42)

Creonte manifesta, por meio da linguagem, que as mulheres não são talhadas para governar, mas para garantir a reprodução daqueles que exercerão o poder. "Levem-nas, escravos, depressa! Agora ficarão reclusas, como mulheres que são, em vez de andarem por aí, livremente" (SÓFOCLES, 2014, p. 48). Incorre, entretanto, em uma negação. Antígona está a conferir ao parentesco a legitimidade do poder. O sangue como fluxo e inflexão para garantir o direito ao luto. Quais sujeitos? Quais margens são as que definem quem merece "viver"?

Se para os gregos a glória é o objetivo de uma vida vivível - obtida por ações grandiosas que serão eternizadas em narrativas históricas -, Antígona ao desafiar as Leis exalta a pena capital como prêmio para sua lealdade à memória do irmão Polinices.

Desafiando o Estado, Antígona reitera o ato desafiante de seu irmão [...] podendo substituí-lo ao se reposicionar territorialmente na configuração de poderes. Deste modo, ela assume a masculinidade ao vencê-la. Em um dado momento o seu ato parece afirmar sua rivalidade e superioridade frente a Polinices. Ela pergunta: "Ainda assim, como eu poderia adquirir maior glória do que enterrando o meu irmão.” (BUTLER, 2001, p. 27)

Ela está a reivindicar o direito à morte, contrapondo-se sobremaneira, ao direito à vida. A questionar padrões normativos que incorrem em problemas epistemológicos, por conseguinte, éticos. Antígona está a inquirir quem são as pessoas passíveis de luto? Isso por compreender que a Vida, sob os auspícios de uma sociedade produtora de mercadorias - em que o objetivo maior é o processo contínuo de acumulação de capital - é uma condição precária que coaduna com o fetichismo do valor. 
Para uma situação mais atual e com apropriação de outras epistemologias e saberes, quais identidades e margens são as linhas que dão alicerce à existência, às relações (públicas ou privadas), às dimensões e esferas integrantes do processo interativo de pessoas, vivendo em coletividades?

Numa passagem de Crenshaw (1991), haveria espaços e tempos para alteridade e interseccionalidades? Ou estaríamos sempre na "torre de Babel"5, fundamentada em uma situação dialética, pois as três esferas da Vida (a lírica, a dramática e a épica, em especial a última que corresponde ao agir político)? Como não observar os "grilhões" que acorrentam, historicamente, as mulheres, em suas pluralidades, diferenças e expressões sociais, étnico-raciais, territoriais e de classe?

As esferas, por essência, não estão/estarão, sem dúvida, em harmonia com as regras do Mercado. Tampouco com a regulação do Estado em garantir a administração das coisas por meio da concorrência e da inovação (leia-se, mais uma vez, do Progresso). Em outras palavras, Antígona descortina a falência do Estado e suas instituições no propósito de minimizar os efeitos da precariedade na sociedade mercantil.

A justificativa de Creonte, em contradição ao alerta do Coro sobre a arrogância ser o caminho da perdição, é um preâmbulo para o estado de exceção. Primeiro a alternativa legal, que concede, por meio do direito consanguíneo, assumir o trono de forma provisória ${ }^{6}$. Para logo em seguida decidir, em anacrônico corroborar com os estudos sobre o Poder de Carl Schmitt, para quem e em quais momentos são orientadas as regras de Tebas.

Antígona, em contraposição, semeia a angústia filosófica. Para ela, com a morte dos dois irmãos, Tebas está ausente de Poder. Portanto, representando uma parte da sociedade dos sem parte (RANCIĖRE, 2014), ela assevera que o direito ao luto caracteriza a essência da democracia real. Entre lutas e lutos, as

\footnotetext{
5 Nessa perspectiva, seria a síndrome da "Torre de Babel" para a construção histórica dos múltiplos discursos que conectam, interferem e dimensionam os Direitos Humanos (MARTíNEZ QUINTEIRO, 2018). Entretanto, predominam em demasia, a "torre de papel", burocratizando a vida, institucionalizando a experiência social - paradoxalmente entre regimes democráticos e ditatoriais.

${ }^{6}$ Os romanos apreendem a lição ao caracterizar o ato de Ditadura. Um período intermediário, de transição, mas sem alienar o poder das Leis, enquanto o Estado é reformado.
} 
dimensões reais da justiça e do campo político também podem detectar opressões, dominações e violências intensificadas.

É importante enfatizar que Antígona, ao desafiar o poder, contraria uma norma estabelecida por Creonte que atinge a comunidade toda. A pena, estar aprisionada em uma caverna - sem qualquer contato humano, alienada de todas as fontes de/para sobrevivência (inclusive a luz do Sol) - é um oximoro: Morte em Vida.

Tal violência é um problema ético. Dialeticamente ela reconhece o poder do Estado, mas desafia a sua representação. Explico-me, com o apoio de Walter Benjamin (1986) em clássico artigo sobre a relação entre violência e poder. Consoante o crítico alemão, se a violência é um meio, o poder se revela na alteridade Leis/Justiça. O segundo se realiza - aqui a influência platônica da República é inconteste - quando há o reconhecimento da "atribuição a cada um da obrigação que the cabe consoante suas próprias aptidões" (PLATÃO, 2018, p. 27).

No entanto, sem uma unidade política que assegure o espaço público para o desenvolvimento dessas aptidões e capacidades inerentes ao humano, a Justiça será apenas apreendida em sistemas que não reconheçam alteridades e, tampouco, prezem pelo reconhecimento do Outro como sujeito ético-moral. Ou seja, o poder se manifesta não pelo Direito, pelo desenvolvimento citadino em busca do equilíbrio da liberdade do indivíduo em relação à soberania coletiva, mas na organização policialesca (imposições normativas) para manutenção da ordem vigente.

Quer dizer: tal ordem jurídica se empenha em estabelecer fins jurídicos em todas as áreas, nas quais os fins pudessem ser almejados adequadamente por indivíduos pelo uso da violência, fins jurídicos que apenas o poder jurídico pode realizar dessa maneira. E o poder jurídico tende a cercear, através de fins jurídicos, os fins naturais - mesmo nas áreas nas quais, em princípio, eles estão livres, dentro de amplos limites, como no caso da educação -, a partir do momento em que eles são almejados com um excesso de violência; haja vista as leis sobre os limites de competência de punições educativas. (BENJAMIN, 1986, p. 162)

O flagelo de Antígona seria, na perspectiva de Creonte, uma punição educativa para os cidadãos e cidadãs de Tebas? Uma maneira do regente em 
transição assegurar a continuidade do poder? Possivelmente. Pois, Antígona ao assumir o feito - "confirmo o que fiz. Não o nego, absolutamente" - está a questionar publicamente a legitimidade do poder, as decisões legais que contradizem a tradição, o ethos coletivo. Está a pôr em dúvida o consenso, que até então é caracterizado na peça teatral na dualidade Corifeu/Coro. Em instâncias democráticas, os silêncios ocupam lugar tão importante quanto as manifestações mais fervorosas.

Primeiro, na representatividade do Coro (da coletividade e da expressão para além do indivíduo), que como a turba segue cegamente os ventos, sem qualquer discernimento frente ao caminho a trilhar:

Divino poder, duvido do que vejo, um assombro, mas não há como negar: essa criança, de fato, é Antígona. Oh, desditosa filha de Édipo, um desditoso pai, o que aconteceu? Trazem-na cativa por haver desobedecido às leis do palácio ou por ter cometido alguma insensatez? (SÓFLOCLES, 2014, p. 39)

Depois, elucidada por Tirésias, essa mesma turba, apreende no ato totalitário um preâmbulo para alienar direitos e a suspeição na condução política:

Já se ergue contra ti, oh Creonte, o ódio de todas as polis cujos filhos não tiveram sepultura, destroçados pelos cães e pelas feras, ou ainda, por grandes aves, que levaram a pestilência dos corpos aos altares. Por teres me provocado, lancei flechas certeiras, como um arqueiro, contra teu coração e do ardor dessa ferida não poderás escapar. (SÓFLOCLES, 2014, p. 66)

Aqui uma clara referência ao imperativo categórico kantiano em associação à negativa hegeliana ${ }^{7}$. Os cidadãos de Tebas estão intimidados pela legislação de Creonte e, por conseguinte, coexistem com uma frágil cidadania. 0 viver é uma ação destinada apenas às necessidades imediatas (que subsistem no espaço privado).

Sem a liberdade política para questionar as decisões do poder, o Estado torna-se um instrumento de regulação e manutenção da estabilidade desse

\footnotetext{
Os dois autores abarcam a questão da alteridade na relação Poder/Liberdade sob a perspectiva da constituição do Estado moderno. Não obstante, na Filosofia do Direito, Hegel resgata a filiação (título) como elemento-chave para eleição de governantes. Desse modo, o filósofo alemão dialeticamente confere a tradição, sob os auspícios do transcendente, a bússola para constituição política.
} 
mesmo poder. O que resulta na ambiguidade da política, quando metamorfoseada em ações policialescas que priorizam, por meio da pena, a educação citadina. Entre outras palavras:

Onde não há liberdade política não pode haver interesse pelo Estado, porque só temos interesse por aquilo em que atuamos e em sua defesa. Na ausência da cidadania, ou da esfera pública, que assegure o livre debate das ideias, o objetivo da vida passa a ser meramente ganhar o pão de cada dia, com maior ou menor grau de conforto ou luxo. O interesse pelo Estado passa a ser meramente egoísta [...] Cria-se um estado de espírito favorável a qualquer religião que promova a passividade a virtude e transforme o autodesprezo e a condição de desgraçado em motivo de glória e orgulho. (COSTA, 2018, p. 4)

Antígona, seguindo essa lógica hegeliana/kantiana, não estaria a omitir suas reais intenções? Não, consoante Butler (2001). A filha de Édipo, em momento algum, busca ocultar seu objetivo: questionar o poder. Nas primeiras falas da peça, em diálogo com a sua irmã Ismênia, a retórica é lapidar (dialética; não persuasiva) sobre o não ocultar que estaria a prestar as honras fúnebres à memória de Polinices: “Ah, podes falar! Mais odioso será o teu silêncio, do que saíres por aí, contando isso a todos" (SÓFOCLES, 2014, p. 28).

Tampouco, quando está diante do rei Creonte:

O que esperavas então? Tuas palavras não me agradam e nada nelas poderia me agradar [...]. Que honra mais sublime poderia haver para mim do que prestar honras fúnebres ao meu irmão? Todos esses diriam que aprovam o que fiz, se o terror não travasse suas línguas. Mas é privilégio do poder tirano fazer e dizer tudo o que deseja. (SÓFOCLES, 2014, p. 43)

Butler (2001) enfatiza que o Estado, na representação de Creonte, é o responsável pela morte do irmão. Atribui às famílias o papel de suprir os exércitos do Estado em suas manifestações de guerra. Portanto, entende que Polinices perece em campo de batalha, juntamente com o outro irmão, Etéocles, para justificar uma estratégia de Poder que, paradoxalmente, alimenta o Estado com a dissolução das famílias que compõem a forma social desse mesmo Estado.

Talvez deva se levar em consideração a surpreendente possibilidade de que o interesse do direito em monopolizar o poder diante do indivíduo não se explica pela intenção de garantir 
os fins jurídicos, mas de garantir o próprio direito. Possibilidade de que o poder, quando não está nas mãos do respectivo direito, o ameaça, não pelos fins que possa almejar, mas pela sua própria existência fora da alçada do direito. (BENJAMIN, 1986, p. 162)

Antígona, ainda sob a perspectiva de Butler:

Ela está a atuar dentro dos limites da lei, está a reivindicar a realização de justiça, ao mesmo tempo que destrói as bases desta lei ao insistir que o luto de seu irmão está acima de qualquer lei que não abarque os próprios cidadãos. A situação dialética é intercambiável entre si. Pois, ao afirmar a particularidade radical de seu irmão, sua atitude se converte em escândalo, em ameaça de destruição da universalidade da lei. (BUTLER, 2001, p. 75)

A incógnita suscitada contínua a mesma: em situações de não reconhecimento de quais Vidas são passíveis de serem vividas, quais são as condições sociais de vida que devem ser preservadas? Independente do sistema de produção vigente e da ideologia preponderante. E se olhássemos para além das lentes de gênero? Se cruzássemos categorias, incorporando as interfaces possíveis e as mais severas críticas que trazem as lentes da interseccionalidade (CRENSHAW, 1991), vasculhando as violências sobrepostas (CAVALCANTI, 2018) e as múltiplas dimensões do ser e do estar em sociedade?

\section{Cassandra e o Angelus Novus: a História é um campo em aberto}

Cassandra - não aquela representação feminina presente na Ilíada de Homero, mas a de Christa Wolf - será nossa mediadora nesta incursão crítica. Para compreendermos o mundo em que estamos inseridos e, desse modo, as relações entre igualdade/justiça nas atribuições de poder, precisamos ponderar uma questão recorrente: o que é viver uma vida boa se uma boa parte da população global está sujeita a alienações econômicas, sociais e políticas que a impedem de gerenciar o seu próprio corpo e, com isso, sua Vida?

Para além do questionamento aristotélico (objetificação de todos os aspectos das vidas humanas), que prima pela condição moral (porquanto, do fundamento ético), na atual sociedade produtora de mercadorias, a afirmação da vida depende de avaliar criticamente as normativas (Estado e suas instituições) que valorizam a vida de forma distinta e não em alteridade. 
Há o reconhecimento de vidas pertencentes ao processo de produção e consumo - estão protegidas juridicamente e apoiadas por redes sociais - e aquelas que são (total ou relativamente) desconsideradas como vidas vivíveis (BUTLER, 2016).

Isso parece ser urgente e necessário no contexto do colapso dos Estados do bem-estar social e naqueles em que as redes sociais de segurança foram destruídas ou tiveram negada a oportunidade de se materializar [...] A precariedade perpassa as categorias identitárias e os mapas multiculturais, criando, assim, a base para uma aliança centrada na oposição à violência de Estado e sua capacidade de produzir, explorar e distribuir condições precárias e para fins de lucro e defesa territorial (BUTLER, 2016, p. 55, grifo nosso)

Cassandra, filha de Príamo, Rei de Tróia, foi consagrada pelo dom da profecia. Na leitura de Wolf, não como uma paradoxal virtude atribuída (ou presenteada?) por Apolo, mas como uma inexorável afronta ao sistema patriarcal. Sim, ela recusou o desejo do deus do Olimpo, não quis ser marcada como mercadoria para depois ser descartada como resíduo de uma manifestação sexual.

A reprimenda divina não se consumou na profecia, mas no descaso social. Cassandra jamais seria ouvida, não passaria de uma louca, presa ou prometida que questiona as vantagens de um sistema voltado para o processo de acumulação em detrimento da Vida. A troiana, não apenas em nosso imaginário, estava antecipando o Angelus Novus benjaminiano em dois milênios:

Existe um quadro de Klee intitulado "Angelus Novus". Nele está representado um anjo, que parece estar a ponto de afastar-se de algo em que crava o seu olhar. Seus olhos estão arregalados, sua boca está aberta e suas asas estão estiradas. O anjo da história tem de parecer assim. Ele tem seu rosto voltado para o passado. Onde uma cadeia de eventos aparece diante de nós, ele enxerga uma única catástrofe que sem cessar amontoa escombros sobre escombros e os arremessa a seus pés. Ele bem que gostaria de demorar-se, de despertar os mortos e juntar os destroços. Mas do paraíso sopra uma tempestade que se emaranhou em suas asas e é tão forte que o anjo não pode mais fechá-las. Essa tempestade o impele irresistivelmente para o futuro, para o qual dá as costas, enquanto o amontoado de escombros diante dele cresce até o céu. O que nós chamamos de progresso é essa tempestade (BENJAMIN, 1986 apud LOWY, 2005, p. 87) 
A insistência em atribuir aos mecanismos de Mercado o controle social é, na perspectiva das Cassandras na contemporaneidade - sendo elas pertencentes a classes, etnias, territórios tão multifacetados -, uma miopia. A mercantilização abstrata no mundo, que utiliza a natureza e os indivíduos como elementos de/para valorização incessante do valor, torna a Vida descartável. Mas qual(is) Vida(s)?

Não há no horizonte próximo uma reorientação teórica que questione o sistema de reprodução social de forma radical (excluída a teoria do valor e do fetiche da mercadoria). Há lampejos de reformulação dos ditames ideológicos e produtivos que assomam o globo, mas não de forma universalizante, apenas com lógicas próprias que atribuem à democracia (real?) o ideário moral e político para o reconhecimento de quais vidas são passíveis de serem vividas. Países são desintegrados por meio da austeridade, da reorientação dos gastos públicos e da dimensão do Estado moderno. Distinto da geopolítica de Cassandra (e de Antígona, por que não?), as minorias são descartadas do sistema da biopolítica por não atenderem aos interesses desse mesmo Mercado.

A loucura, na forma social, persiste. Da Tebas de Antígona e da Tróia de Cassandra à Grécia e à Turquia da Modernidade:

A inconsciência que acabei mergulhando foi precedida de uma centelha de triunfo - o que pode parecer curioso apenas para aqueles que desconhecem a astuta relação existente entre as enfermidades e nossas manifestações reprimidas. Essa foi a crise, e durante algum tempo minha vida se dividiu entre o tempo antes da crise e o tempo depois da crise - uma forma de calcular o tempo que em breve se tornou sem valor, como tantas outras, mais tarde [...] Sempre me permiti prazos de cegueira parcial. Tornar-me vidente de um só golpe me teria sido fatal. (WOLF, 1990, p. 48)

As vidas precárias são o lixo da sociedade de consumo. Não são resíduos. Configuram-se como descartes-objetos e não sujeitos históricos. Não há espaço (leia-se interesse econômico) em integrá-las ao sistema. Tampouco promover leis que minimizem a situação de violência a que estão cotidianamente expostas.

A perspectiva democrática, um engodo das oligarquias financeiras vigentes, é amparada por uma legislação que não reconhece aquela parte de 
sociedade dos sem parte (RANCIĖRE, 2014) que exige direito a ter direitos. A biopolítica - racial, étnica, territorial - também é uma questão de gênero. A inserção relativa das mulheres neste universo da acumulação é uma falácia da contemporaneidade, pois os salários e as posições de mando são diferenciados (sempre) para baixo. A Ágora da Modernidade é apenas o Mercado, o local para estabelecer irracionalmente a economia empresarial do lucro em detrimento da Vida.

Durante muito tempo fui incapaz de compreender isso: que nem todos podiam ver o que eu via. Que não percebiam a forma nua e sem sentido dos acontecimentos. Pensava que estariam me fazendo de idiota. Mas não, acreditavam no que diziam. Isso tem que ter um sentido. Como se fôssemos formigas: um povo cego atirando-se no fosso, afogando-se, formando a ponte para poucos sobreviventes, o núcleo de um novo povo. Como formigas nos atiramos em qualquer incêndio. Em qualquer inundação. Em qualquer rio de sangue. Apenas para não ver. Ver o quê? Nós mesmos. (RANCIÉRE, 2014, p. 50)

Uma integração parcial, seletiva de Vidas é, na leitura moderna da biopolítica, a barbárie contemporânea: a necropolítica (MBEMBE, 2016). Não há como eliminar, por meio da política, o sistema de produção social vigente, se a própria política é um dos polos desse mesmo campo histórico da economização abstrata do mundo; e o valor, o seu sujeito automático (KURZ, 1997; 2015).

Aqui, retomamos o "asselvajamento do patriarcado" asseverado por Scholz (2017) para questionar o nosso tema central: vidas vivíveis. Nos momentos de crise, a carga e o fardo de nosso tempo histórico recaem sobre os ombros femininos. A integração de atividades (antes) dissociadas do processo de produção - o cuidar, por exemplo - busca minimizar os efeitos da contradição inerente ao processo de acumulação, o que a ensaísta alemã denomina de "mercantilização de todos os aspectos da vida". A crise social resultante delimita quais são essas vidas passíveis de proteção jurídica e apoio nas redes sociais. Afinal, o fundamento ético é suplantado pelo ethos coletivo que, na representação do Estado e suas instituições, legitima a violência.

$\mathrm{Na}$ cegueira coletiva para interpretar as razões da crise, a integração feminina em rincões de exclusividade masculina acirra a barreira contra uma (aparente) luta emancipatória. Na esfera econômica, o jogo remete ao 
reconhecimento não da questão de gênero, mas da solvência social, do direito tautológico determinado pelas regras de mercado.

As condições críticas da vida democrática são expostas. Não há espaço/tempo para integração de todos em um sistema que prima pela concorrência e pelo individualismo. Resistências populares são manifestações para desfraldar a precariedade como condição sine qua non para manutenção de um sistema falido em seus fundamentos: a acumulação com base no trabalho abstrato na forma mercadoria.

Transformações sociais não coadunam com reformas no sistema de produção. A condição precária que se alastra no globo não será suplantada com o reconhecimento das minorias na forma mercadoria. O momento histórico é para questionar os pilares históricos do atual estágio da crise.

(Re)interpretar e valorizar o que já foi produzido como crítica social, desde os eixos produzidos pela Escola de Frankfurt e da Teoria Crítica em suas expressões contemporâneas, são mais que premissas e urgências de tempos sombrios, nos quais a decisão de quem vive ainda traz ranços e traços coloniais, patriarcais e racistas contundentes.

(Re)fundar o social como elemento ético, estético e plural projeta-se como potência anti-precarização de todos os aspectos das vidas (para este artigo, especialmente de mulheres, em suas pluralidades e expressões de diversidade).

Talvez tenha sido sob uma luminosidade como esta, caso o navio dos aqueus tenha partido de Tróia ao entardecer, que as prisioneiras troianas comprimidas na proa tenham visto pela última vez as ruínas de sua cidade e do litoral natal. Essa visão deve ter aumentado sua dor e ao mesmo tempo ancorado esse amor do qual necessitariam para viver no estrangeiro. Mas entre os narradores que escreveram sobre elas, e que foram testemunhas desses acontecimentos, nenhum deles mencionou essa luz. (WOLF, 1990, p. 186) 


\section{Referências}

ARENDT, Hannah. Entre o passado e o futuro: oito exercícios sobre o pensamento político. Lisboa: Relógio D’Água, 2006.

BENJAMIN, Walter. Crítica da violência - crítica do poder. In: Documentos de cultura, documentos de barbárie (escritos escolhidos). São Paulo: Cultrix; Editora da Universidade de São Paulo, 1986. p. 160-175.

BUTLER, Judith. Vida Precária. Contemporânea, Florianópolis, n. 1, p. 13-33, jan./jun. 2011.

BUTLER, Judith. Corpos em aliança e a politica das ruas: notas para uma teoria performativa de assembléia. Rio de Janeiro: Civilização Brasileira, 2018.

BUTLER, Judith. El grito de Antigona. Barcelona: El Roure Editorial, 2001.

BUTLER, Judith. Quadros de guerra: quando a vida é passível de luto? Rio de Janeiro: Civilização Brasileira, 2016.

CAVALCANTI, Vanessa Ribeiro Simon. Violência(s) sobreposta(s): contextos, tendências e abordagens num cenário de mudanças. In: DIAS, Isabel (org.). Violência doméstica e de gênero: uma abordagem multi-disciplinar. Lisboa: Pactor, 2018. p. 97-122.

COSTA, Iná Camargo. Sérgio Buarque, o "Homem Cordial" e uma crítica inepta. Outras Palavras, 11 maio 2018. Disponível em:

https://outraspalavras.net/poeticas/sergio-buarque-o-homem-cordial-e-umacritica-inepta/. Acesso em: 16 dez. 2019.

CRENSHAW, Kimberlé. Mapping the margins: intersectionality, identity politics, and violence against women of color. Stanford Law Review, Stanford, v. 43, p. 1241-1299, jul. 1991.

HARVEY, David. O enigma do capital e as crises do capitalismo. São Paulo: Boitempo, 2011.

KURZ, Robert. Os últimos combates. Petrópolis: Vozes, 1997.

KURZ, Robert. Poder mundial e dinheiro mundial: crônicas do capitalismo em declínio. Rio de Janeiro: Conseqüência, 2015.

LOWY, Michael. Walter Benjamin: Aviso de incêndio: Uma leitura das teses

"Sobre o conceito de História". São Paulo: Boitempo, 2005. 
MARTÍNEZ QUINTEIRO, Maria Esther. El discurso de los derechos humanos en perspectiva histórica: el síndrome de la torre de Babel. In: PANDO

BALLESTEROS, María de la Paz; MUÑOZ RAMÍREZ, Alicia; GARRIDO RODRÍGUEZ, Pedro (eds.). Pasado y presente de los derechos humanos: mirando al futuro.

Salamanca: Ediciones de la Universidad de Salamanca, 2018. p. 41-60.

MBEMBE, Achille. Necropolítica. Arte \& Ensaios, Revista do PPGAV/EBA/UFRJ, Rio de Janeiro, n. 32, dez. 2016. p. 123-151. Disponível em:

https://revistas.ufrj.br/index.php/ae/article/view/8993/7169. Acesso em: 05 jan. 2020.

MELVILLE, Herman. Bartleby, o escriturário. Porto Alaegre: L\&PM, 2017

PLATÃO. A república. São Paulo: Martin Claret, 2018.

RANCIĖRE, Jacques. O ódio à democracia. São Paulo: Boitempo, 2014.

SCHOLZ, Roswitha. O valor é o homem: teses sobre a socialização pelo valor e a relação entre os sexos. Novos Estudos CEBRAP, São Paulo, n. 45, p. 15-36, jul. 1996. Disponível em: http://www.obeco-online.org/rst1.htm. Acesso em: 24 nov. 2019.

SCHOLZ, Roswitha. A teoria da cisão de gêneros e a teoria crítica de Adorno. In: CEVASCO, Maria Elisa; OHATA, Milton (org.). Um crítico na periferia do capitalismo: reflexões sobre a obra de Roberto Schwarz. São Paulo: Companhia das Letras, 2007. p. 168-180. Disponível em:

http://obeco.planetaclix.pt/roswitha-scholz9.htm. Acesso em: 24 nov. 2019.

SCHOLZ, Roswitha. Crítica da dissociação-valor e teoria crítica. [Lisboa: Exit!], 2017. Disponível em http://www.obeco-online.org/roswitha_scholz28.htm.

Acesso em: 02 dez. 2020.

SÓFOCLES. Antigona. São Paulo: Martin Claret, 2014.

WOLF, Christa. Cassandra. São Paulo: Estação Liberdade, 1990.

Universidade do Estado de Santa Catarina - UDESC

Programa de Pós-Graduação em História - PPGH

Revista Tempo e Argumento

Volume 12 - Número 31 - Ano 2020 tempoeargumento@gmail.com 